\title{
Shopping Via Mobile Phones in the Central European Czech Republic Market
}

\author{
Lenka Lustigová ${ }^{1}$, Daniela Š́lková ${ }^{2}$ \\ ${ }^{1}$ Department of Languages, Faculty of Economics and Management, Czech University of Life Sciences \\ Prague, Czech Republic \\ ${ }^{2}$ Department of Trade and Finance, Faculty of Economics and Management, Czech University of Life \\ Sciences Prague, Czech Republic
}

\begin{abstract}
Information and, in particular, mobile technologies play an increasingly important role in the economic environment. The article surveys attitudes of Central European Czech customers to mobile phone usage for purchasing products and payments. Based on the results that were gained by the survey the paper suggests opportunities for further business development in the stated areas. The data was obtained by a combination of quantitative and qualitative research using a standardised questionnaire survey among respondents of all age groups. Data was collected throughout the year 2017. By random and targeted selection, 1335 respondents were selected for the survey. Based on the survey data analysis it was observed that Internet shopping via mobile phones has not been widespread up to now. Entrance tickets and fare tickets, electronics, clothing, and cosmetics are the most frequently purchased products via mobile phones. Despite an enormous potential of smartphones current users have not deployed their functions entirely so far.
\end{abstract}

\section{Keywords}

Customer, ICT, mobile device, mobile payment, retail consumers' goods, retail store, shopping.

Lustigová, L. and Š́lková, D. (2018) "Shopping Via Mobile Phones in the Central European Czech Republic Market", AGRIS on-line Papers in Economics and Informatics, Vol. 10, No. 4, pp. 49-58. ISSN 1804-1930. DOI 10.7160/aol.2018.100405.

\section{Introduction}

Information and, in particular, mobile technologies play an increasingly important role in the economic environment. Internet connection is perceived as a key factor in the further development of society (Vaněk et al., 2010a). The Internet can generally be recognised as a means of working with information. The rapid growth of the Internet as a medium for communications, as a channel of distribution, and as a way of reaching individual customers efficiently and effectively 'has not only affected marketing managers' decision-making but has created the need for new directions in marketing thought'. (Steckel et al., 2005). Highly educated people use the Internet more actively, and their use is more information oriented whereas the less educated ones seem to be interested particularly in the entertainment functions of the Internet (Bonfadelli, 2002). Many strategies like 'mass customization, relationship marketing, interactive marketing, etc. have gained increased attention, in part, from advancements in manufacturing and information technology'. (Varki and Rust, 1998) Mobile phones represent this specific platform, which is becoming increasingly important nowadays. However, further development of shopping via mobile phones, which offers a vast amount of possibilities, depends largely on the acceptance of new technologies by customers (Bruner and Kumar, 2005). Nevertheless, certain prospective customers may not accept the services offered despite their widespread availability (Wang et al., 2006); the fear of privacy loss accounts for the most common reason (Xu and Gupta, 2009). Moreover, as demonstrated by some studies, the adoption of new mobile services by European users is slower than expected (Carlsson et al., 2006). As Inman and Nikolovova (2017) suggest "retailers are understandably overwhelmed by the options and may adopt technologies without a clear picture of both how they fit into their strategy and, potentially more important, how shoppers will react." Furthermore, intensive use of smartphones and specific mobile applications 
has been influenced by gender, age, and so-called 'personal innovativeness' significantly (Jung et al., 2013).

Mobile Internet connectivity enables a user's localisation and targeted advertising (certainly, with the user's permission and an offer the customer might be interested in). Proximity marketing can be perceived as an emerging form of marketing built upon advances in wireless and social technology (Levesque et al., 2015). However, certain rigors were observed when applying proximity marketing for business purposes. According to Ojala et al. (2012), merely $1.1 \%$ of the devices received the message and on average $3.3 \%$ of the device owners signed up for the marketing campaign.

The use of ICT and mobile devices is becoming increasingly visible in all sectors (Vaněk et al., 2010b). ICT development and access to all mobile services stands as a matter of the utmost importance (Köppelová and Jindrová, 2017). Business operations and customer contact via mobile devices has a large potential due to the very personal and intimate nature of the devices and high targeting possibilities (Aalto et al., 2004). The mobile world can be referred to as a place where business takes place anytime and anywhere (Balasubramanian et al., 2002). The expansion of mobile phones (and smartphones in particular) offers numerous new business opportunities. Consumers are more accessible through these devices, and communication via mobile Internet can be interactive more easily (Ferris, 2007). Likewise, this is confirmed by estimates of future global smartphone sale volumes provided by Canalys (2013), independent analysts, who predicted a rise in smartphone sales up to $17.9 \%$ between 2012 and 2017 , to the detriment of regular mobile phones. It is believed that, 'with the introduction of Apple's iPhone into the market, the mobile Internet promises to be one of the most important technological developments for the future' (West and Mace, 2010 in Koenigstorfer and Groeppel-Klein, 2012: 917). However, as further stated by Koenigstorfer and Groeppel-Klein (2012: 917), 'forecasts for the diffusion of both the mobile Internet and mobile commerce worldwide were overoptimistic'.

In the Czech Republic, smartphones for Internet browsing are used by up to $52 \%$ of users, who establish the continuously expanding group of potential customers of sales and marketing via mobile phones. Mobile phones are increasingly used to browse web presentations; thereby companies are bound to customise their websites regarding the format or, as the case may be, develop mobile phone versions of their websites. Another option to optimise mobile phones websites is to develop an application based on the specific platforms (for example, iOS, Android, BlackBerry, etc.). Since such applications are developed directly for the mobile phone specific operating system, brand new features can be designed. Generally, such new properties are not available for mobile phone websites as the data is extensive or the sites are not functional in all mobile phone operating systems.

The survey aims to investigate the forms of mobile phone use for shopping and payment purposes. Furthermore, it provides an overview of the kinds of retail consumers' goods that are most frequently purchased via mobile devices.

\section{Materials and methods}

Consumer behaviour research on use of mobile phones focused on identifying key factors that affect mobile phone usage in relation to consumer purchases. The data was obtained by a combination of quantitative and qualitative research using a standardised questionnaire survey among respondents of all age groups. Data was collected at the end of 2017 in the Czech Republic. A portion of the respondents completed the questionnaire electronically using the Internet, while the other respondents were addressed in person. By random and targeted selection, 1335 respondents were selected for the survey.

The questionnaire contained a maximum of 30 questions. The number of questions was dependent on the usage of the mobile phone; the questionnaire focused on users of mobile phones, smartphones in particular. On average, respondents answered 15 questions. Initial questions aimed to survey basic facts associated with the influence of the operating system used and the ways of utilising mobile phones. Furthermore, the respondents provided information on mobile phone Internet access emphasising wireless Wi-Fi access, especially in public places. In the next section, the questionnaire focused on identifying a preferred website customisation for mobile phone displays and the extent of applications' use to gather various information. In addition, the survey was comprised of issues linked with mobile marketing perceptions held by mobile phone users, feasibility of mobile phone payments and, likewise, customers' attitudes towards mobile 
shopping. The last part of the questionnaire contained demographic characteristics of the respondents.

The data was analysed based on mathematical and statistical methods. Simple Microsoft Office Excel 2011 contingency tables were created to provide interrelations between selected variables. Subsequently, they were construed in details. Interpretation of statistical data, analysis, and synthesis were performed as constituent methods. Based on the measurable data, structured tables were created using a quantitative analysis of the numerous responses for selected factors. Unquantifiable factor data was analysed by an analogy method based on the previously performed qualitative research results.

The respondent reference group consisted of $64.9 \%$ females and $35.1 \%$ males. An age structure of the respondents followed by education structure is demonstrated in Table 1.

Contingency tables were created as a tool to analyse actual interrelations between particular demographic characteristics (gender, age, economic status, size of residence) and the survey data. More thorough research focused on mobile phone operation systems, particular forms of mobile phone use with regards to searching the Internet, social network connections, and game playing is, however, necessary. Special attention was given to advertisements through free Wi-Fi connection in public places. Moreover, mobile applications used by customers to search for various information were analysed and, likewise, particular forms of mobile marketing and mobile payment methods were investigated. Simultaneously, the analysis focused on Internet shopping and activities related to regular retail stores shopping, i.e. product quality assurance, price analysis, and store locations, in particular.

\section{Results and discussion}

The data demonstrated that mobile technologies are utilised preferably by young people between the ages of 16 to 24 (almost $50 \%$ of the respondents) and the group of productive age customers that are 25 to 34 years old (almost 28\%). In total, $22.7 \%$ respondents were older than 35 years and $3.3 \%$ were $55+$ years old. Considering the younger age group (from 16 to 24), mobile phones constitute an inseparable part of their lives, and many of these respondents cannot imagine their lives without such technologies. Individuals aged from 25 to 44 use mobile technologies primarily as a necessary part of their both private and work lives.

A prevailing number of the respondents own a mobile phone $(99.5 \%)$. However, so-called smart phones are used just by $61.5 \%$ of them. Almost everybody owns a mobile phone; on the contrary, smart phones have only been recently establishing its market position. Obviously, an increase in smart phone use can be expected with regards to various complementary functions offered to the users (Šimek et al., 2014).

Despite the extensive expansion of smart mobile phones and their capabilities (including shopping anytime and anywhere), only $19 \%$ of the respondents use their mobile phones for Internet shopping; the remaining $81 \%$ prefer other forms of Internet shopping, preferably by shopping on a computer. The customers who utilise mobile phone shopping value the speed, accessibility, and comfort of the purchase. Satisfaction of the final users with any service is directly linked with the network quality and performance (Habibi et al., 2016). They appreciate the effective use of their travel time, the ability to purchase retail consumers' goods on the way home, QR code scanning that displays a particular product or complete invoice data, and facilitate a payment. People often purchase mobile phone games, which have been increasing both in quality and hardware requirements. Data service quality and multimedia application requirements of the final users keep growing (Olwal, 2016). (Figure 1)

The Czech Republic is also on the top position in the number of e-shops per capita in the Europe (Ulman et al., 2016). Smart phones can be used during the shopping process to expand information

\begin{tabular}{|c|c|c|c|c|c|c|}
\hline Less than 15 & $16-24$ & $25-34$ & $35-44$ & $45-54$ & $55-64$ & 65 plus \\
\hline $2.6 \%$ & $46.9 \%$ & $27.8 \%$ & $13.2 \%$ & $6.2 \%$ & $2.6 \%$ & $0.7 \%$ \\
\hline $\begin{array}{l}\text { Secondary incl. vocational } \\
\text { (with no graduation exam) }\end{array}$ & $\begin{array}{c}\text { Elementary } \\
\text { (incl. unfinished) }\end{array}$ & \multicolumn{3}{|c|}{$\begin{array}{c}\text { University } \\
\text { (bachelor, master) }\end{array}$} & $\begin{array}{c}\text { Secondary incl. vocational } \\
\text { (with graduation exam) }\end{array}$ \\
\hline \multicolumn{2}{|c|}{$12.1 \%$} & $35.3 \%$ & $45.4 \%$ \\
\hline
\end{tabular}

Source: Authors' research, 2017

Table 1: Demographic characteristics of the respondents (age structure and highest education obtained). 


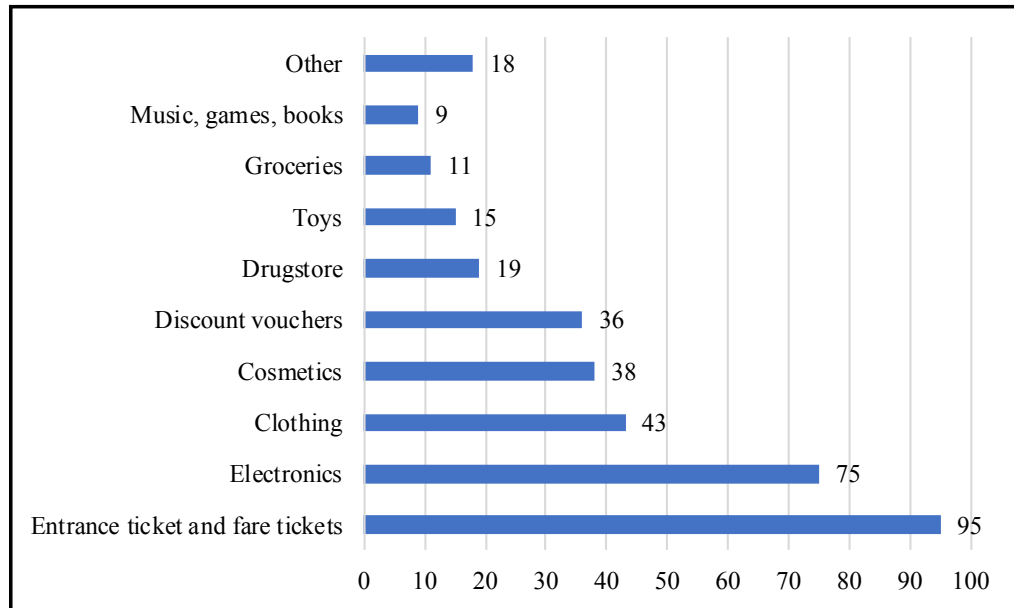

Source: Authors' research, 2017

Figure 1: Retail consumers' goods and services most frequently purchased via mobile phone.

on the product. The customer may discover the product rating, opinions, and experiences of other customers regarding the product's quality and functions. Moreover, product price may be compared in numerous internet shops and, thus, the cheapest purchase can be located (either in a physical retail store or electronically including additional transportation costs or time used for product personal collection). In the case of a specific product or store in need, the customer may locate the particular product or store very easily. Numerous mobile applications and websites facilitate comparisons and ratings of almost all products on the market. Mobile technologies represent active opportunity for retailers to influence decision-making process of numerous consumers (Faulds et al., 2018). However, sufficient mobile network coverage is a substantial prerequisite of such mobile phone activities (Habibi et al., 2017).

\section{Payment methods}

Payments constitute inseparable part of Internet shopping. Effortlessness and security stand for the efficiency and frequency of mobile payment use. (Shankar and Datta, 2018). However, mobile phone payments can be facilitated even without Internet connection. Nowadays, numerous brand new technologies support contactless mobile payments or easy access to internet banking. Both retailers and consumers report growing interest in mobile payments (Liebana-Cabanillas et al., 2018).

M-payments offer numerous benefits in comparison with traditional payment services (Johnson et al., 2018). It was observed that m-payment is the most used method of payment. It was deployed by up to $37 \%$ of males of the age from 25 to 34 .
Likewise, almost $30 \%$ of females adopted such services; however, they are more favourable among females of the age from 35 to 44 . The survey demonstrated that education does not affect a mobile payment adoption significantly, with the exception of university graduates. Almost one third of university graduates perform mobile payments regularly. Considering the age range, the results show that m-payments are generally not used by males of the age from 55 to 65 and by males under the age of 15 . It was claimed that females perform mobile payments across all age categories.

Quick response $(\mathrm{QR})$ code payment has become a significant component of mobile transactions (Zhu et al., 2016). A QR payment is the second most common type of payment that is the most frequently used by males from the ages of 16 to 44 . Generally, other age categories stated no mobile payment performance. Regarding females, the QR payment is facilitated across all age categories; however, it is noticeable that the most significant usage is applied by middle-aged females aged 35 to 44 . On average, females than males perform QR payments more frequently. NFC accounts for another important technology utilised for regular shopping payments. However, payment security is more difficult to secure due to the NFC user authentication (Chen et al., 2017). NFC technologies, NFC payments, and NFC tags in particular were observed to be the least adopted types of payment. The NFC payment is the most frequently used in the age category of 16 to 44 ; nevertheless, the utilisation rate is gradually declining and, simultaneously, the demand for this type of technology has been decreasing. Such payments are not deployed at all by males of the age 45 plus and, as the case may be, females employ it minimally. On the contrary, 
NFC tags are being used only to a limited extent by males aged 25 to 44 . The remaining age categories do not use them at all. The use of NFC tags by females is even lower and, if at all, they are used by younger age groups. Likewise, it was observed that education does not barely impacts NFC payment adoption.

\section{Shopping with mobile phones}

Based on the survey data analysis, it was observed that internet shopping via mobile phones has not been widespread up to now in spite of high rate of mobile phone use (Marriott and Williams, 2018). It was demonstrated that there is a relation between mobile internet general use and an increasing trend in mobile internet shopping (Citrin et al., 2000). A monitored group of the respondents demonstrated very little usage of mobile phones for shopping. Neither education nor gender affect the actual data substantially. Merely a slightly higher interest rate was proved for males (approximately one third, on average) and lower for females (approximately just one seventh, on average). Simultaneously, this form of shopping is impacted by economic status to a very little extent.

Moreover, age accounts for an important demographic indicated by the research. It was recognised that a higher proportion of males across all age categories has adopted such a shopping method. Nevertheless, on an average $72 \%$ of them (similarly, $80 \%$ of females) do not use mobile phones for shopping purposes entirely. The only male age group showing an extreme value is the age group of 15 years and less; the interest is zero. Possibly, such behaviour is caused by a lack of funds. In the female category, it was noticed that women between the ages of 16 and 24 and older women aged 55 to 64 in particular are the least likely to shop via mobile phones. A higher willingness to this type of purchasing was observed in the middle age group of 25 to 44. Age and education levels account for an important factor in m-commerce use (Chong, 2013). Just under 20\% of people have adopted the method of shopping via mobile phones. These users buy entrance tickets and fare tickets, electronics, clothing, cosmetics, and, when the opportunity arises, discount vouchers.

Purchases of entrance tickets and fare tickets by mobile phones (see the Figure 2 below) are most frequently performed both by males and by females of the age of 25 to 34 . Remarkably, this type of product is purchased more by males and, at the same time, a significant drop in the number of these purchases by females over the age of 34 was observed.

Electronics are more frequently purchased via mobile phones by males up to the age of 44 when their interest diminishes considerably. On the contrary, females purchase electronics via their mobile phones merely up to the age of 34 when this method of purchasing electronics declines rapidly.

Internet shopping for clothing is mostly performed by females of the age from 16 to 34 when their willingness to browse and compare budget-wise offers is substantially high. Obviously, these women are less likely to tolerate the risk of choosing the wrong size of a piece of clothing or, as the case may be, they choose retail stores in which they can easily return purchased clothes or try it on before buying. It was discerning that men are not interested in Internet shopping for clothes extensively (Figure 3).

Cosmetics belong to favourable retail consumers' goods, which is often purchased via mobile phones. It was recognised that it is a preferred method

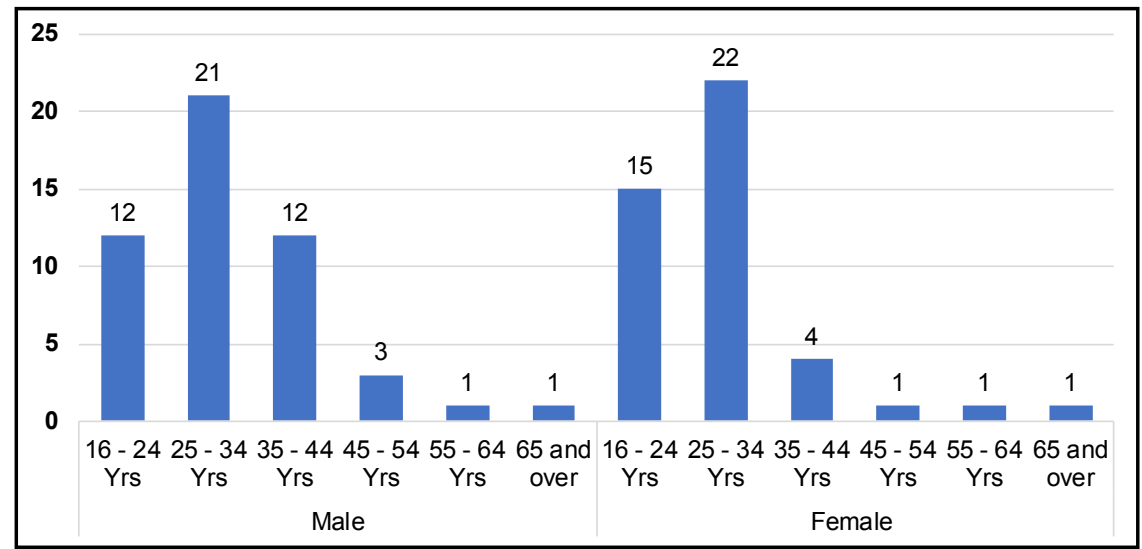

Source: Authors' research, 2017

Figure 2: Internet shopping via mobile phones - entrance tickets and fare tickets. 


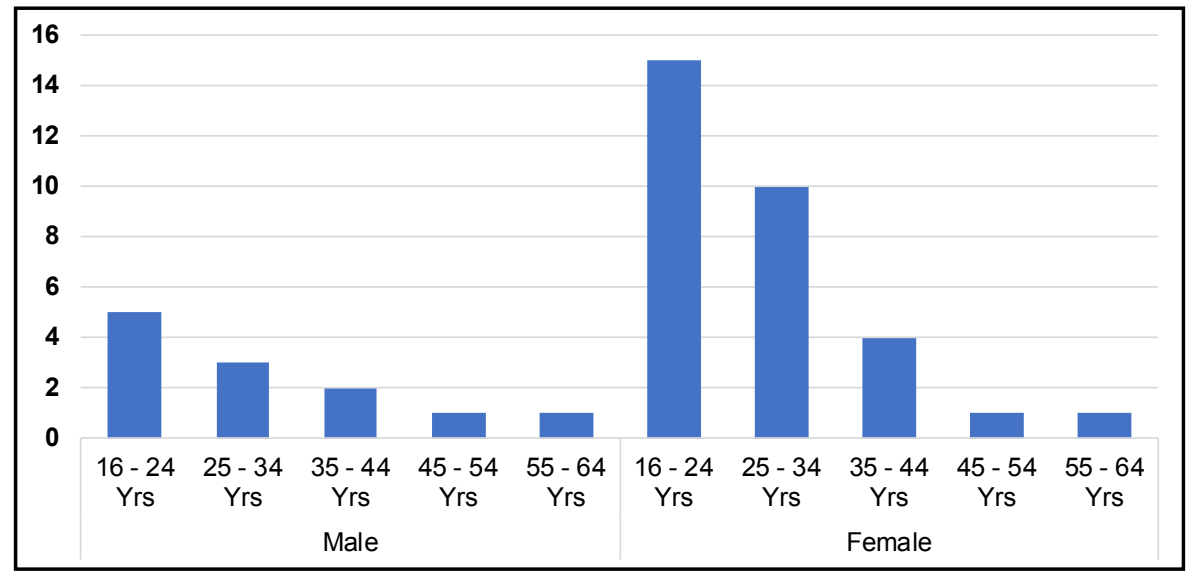

Source: Authors' research, 2017

Figure 3: Internet shopping via mobile phones - clothing.

of shopping among women between the ages of 16 and 44. Obviously, the following reasons stand for such a method of shopping: significantly lower price, unavailability of the brand or product in the physical retail stores or the convenience of shopping. It is worth noticing that a higher rate of males purchasing was detected (as opposed to the clothing category that clearly does not attract men's attention). The highest proportion of Internet purchases by mobile phones is executed by men aged 35 to 44, who may shop for gifts for their spouses or just want to look youthful and purchase beauty products for themselves.

\section{Retail store location search}

Store location search is applied mostly by females of the ages from 16 to 24 ; i.e. up to $30 \%$ of the total respondents who use this function. On the contrary, males of the same age category significantly less deploy this function (almost by 50\% less than by women). In the second age category of 25 to 34 , the data for males and females is equal; however, higher age categories use the function minimally, or they do not adopt it entirely. Most likely, lower shopping enthusiasm of males in general accounts for the reasons of such a trend.

\section{Comparison of product prices}

It was noticed that females considerably utilise mobile phones more to compare Internet product prices; specifically, the percentage of these women is $50 \%$ higher than of the men within the age from 16 to 24 . In the subsequent age category of 25 to 34 years, the data is more equal and, furthermore, in higher age categories the function is hardly deployed. Similarly, the structure of people who use mobile phones to check customer forums to determine the quality and feasibility of products before purchasing them is comparable to those who compare product prices and, thus, it is not being specified within this paper repeatedly.

\section{Recommendations for further development} of trade activities via mobile phones

Research has demonstrated that so-called smartphones are being increasingly utilised among consumers, and their increasing market share can be expected to grow at the detriment of ordinary mobile phones. Owing to fast advancements of these technologies, new opportunities for both traders and marketers arise. From the traders' point of view, it will be important to expand alternatives for using different types of mobile payments in the future. Such an expansion of payment options can attract new customers or directly affect the decision to purchase. The decision-making process on a purchase could be influenced by, for example, the customer not having enough cash available or the retailer not having adequate funds to give the change back. Likewise, administrative procedures associated with invoice settlement could be potentially simplified and accelerated with QR payments. Additionally, retailers would be able to focus on products that are purchased via mobile phones and optimise the user-website interface. For example, restructuring a cosmetics e-shop may emphasise and promote beauty care products focusing on females aged 16 to 24 and males of the age from 35 to 44 . Furthermore, in these types of e-shops it would be feasible to offer male and female gift products separately to simplify customers' choice of presents.

In some market sectors, free access to wireless Wi-Fi is already very common (and often necessary) as demonstrated within the accommodation or boarding industry, for example. Wi-Fi is 
a required standard in most restaurant facilities. However, Wi-Fi connection does not need to be installed solely for restaurant customers; it could be utilised for information and promotion purposes. It could be employed to build and promote brand awareness, extend the existing client database, or advertise new products and special offers.

These new mobile technologies bring enormous opportunities for traders; nevertheless, they stand for a substantial threat simultaneously. The consumer is significantly more knowledgeable and well-informed and, furthermore, he/she is able to compare prices and quality of retail consumers' goods, all online in the store. On the other hand, a customer who does not utilise these options is at a disadvantage as he/she relies solely on information that the retailer chooses to provide. Moreover, the consumer is able to locate specific retail stores (via the Internet or GPS embedded in a mobile phone) and desired goods. The traders are threatened at the same time as their competitors become more accessible even for a visitor who is not aware of the local distribution of stores. Owing to the mobile phone and its up-to-date functions, the location of specific stores within the vicinity and selection of goods before actually entering the store, restaurant, or boarding facility is currently very simple.

Similarly, mobile technologies are becoming more important in marketing campaign development. None of the larger companies ought to ignore this kind of communication tool. With regard to operating systems, the research has demonstrated that if companies focus on higher educated consumers, they should not neglect the BlackBerry operating system. Within the sector of discount portals, application developers should concentrate especially on younger women under the age of 34, who adhere the most to this type of shopping. Free distribution of applications that provide information about the company, business, and products is considered a very soft and natural form of promotion. Consumers download this type of application by themselves because it is linked with certain benefits, for example, advanced orientation in the assortment, awareness of special offers or, as the case may be, simplification of orders and payments made.

The suggestions stated above represent several pieces of advice for company strategic planning processes in the sphere of mobile interaction in shopping. Specific recommendations would have to be customised considering the requirements of a specific company, its product portfolio, and customer structure.

\section{Conclusion}

Despite their enormous potential, current users have not deployed smartphone functions entirely so far, even though some features would be highly beneficial for them. For example, searching for specific products and purchasing retail consumers' goods from e-shops via mobile devices have been almost unused. Similarly, following online customer forums or utilising navigation properties to locate retail stores have not been utilised thoroughly. Concurrently, such services may be highly beneficial for the customers and even potentially save large amounts of money when purchasing goods and services. From the discussion above, it can be derived that new opportunities are spreading out in front of both companies and customers; however, new threats are also emerging. It is of utmost importance to respond to them adequately and prepare thoroughly.

\section{Acknowledgements}

This article was supported by the Internal Grant Agency (IGA) of the Faculty of Economics and Management, Czech University of Life Sciences Prague (FEM CULS), No. 20171014 - "Optimizing distribution of food intended for special nutrition with a focus on gluten-free products".

\section{Corresponding authors}

Lenka Lustigová, M.A.

Department of Languages, Faculty of Economics and Management, Czech University of Life Sciences Prague, Kamýcká 129, 16500 Prague - Suchdol, Czech Republic Phone: +42022438 2842, Email: lustigova@pef.czu.cz 


\section{References}

[1] Aalto, L., Göthlin, N., Korhonen, J. and Ojala, T. (2004) "Bluetooth and WAP push based locationaware mobile advertising system", Proceedings of the Second International Conference on Mobile Systems, Applications and Services, MobiSys 2004, pp. 49-58, New York, NY, USA, ACM Press. DOI 10.1145/990064.990073.

[2] Balasubramanian, S., Peterson, R. A. and Jarvenpaa, S. L. (2002) "Exploring the implications of M-commerce for markets and marketing“, Journal of the Academy of Marketing Science, Vol. 30, No. 4, pp. 348-361, ISSN 00920703.

[3] Bonfadelli, H. (2002) "The Internet and knowledge gaps: A theoretical and empirical investigation“, European Journal of Communication, Vol. 17, No. 1, pp. 65-84, ISSN 02673231. DOI 10.1177/0267323102017001607.

[4] Bruner II. G. C. and Kumar, A. (2005) "Explaining consumer acceptance of handheld Internet devices“, Journal of Business Research, Vol. 58, No. 5, pp. 553-558, ISSN 01482963. DOI 10.1016/j.jbusres.2003.08.002.

[5] Canalys (2013) "Mobile device market to reach 2.6 billion units by 2016". [Online], Available: http://www.canalys.com/newsroom/mobile-device-market-reach-26-billion-units-2016. [Accessed 4 April, 2018].

[6] Carlsson, C., Carlsson, J., Hyvönen, K., Puhakainen, J. and Walden, P. (2006) "Adoption of mobile devices/services - Searching for answers with the UTAUT", Proceedings of the Annual Hawaii International Conference on System Sciences, Vol. 6, 132a p., ISSN 15301605.

[7] Citrin, A. V., Sprott, D. E., Silverman, S. N. and Stem, D. E (2000) "Adoption of Internet shopping: the role of consumer innovativeness“, Industrial Management \& Data systems, Vol. 100, No. 7, pp. 294-300. ISSN 0263-5577. DOI 10.1108/02635570010304806.

[8] Chen, X. Y., Choi, K., and Chae, K. (2017) "A Secure and Efficient Key Authentication Using Bilinear Pairing for NFC Mobile Payment Service“, Wireless Personal Communications, Vol. 97, No. 1, pp. 1-17. E-ISSN 1572-834X, ISSN 0929-6212. DOI 10.1007/s11277-017-4261-9.

[9] Chong, A.Y. L. (2013) "Mobile commerce usage activities: The roles of demographic and motivation variables“, Technological Forecasting and Social Change, Vol. 80, No. 7, pp. 1350-1359. ISSN 0040-1625. DOI 10.1016/j.techfore.2012.12.011.

[10] Faulds, D. J., Mangold, W. G., Raju, P. S. and Valsalan, S. (2018) "The mobile shopping revolution: Redefining the consumer decision process“, Business Horizons, Vol. 61, No. 2, pp. 323-338. ISSN 0007-6813. DOI 10.1016/j.bushor.2017.11.012.

[11] Ferris, M. (2007) "Insights on mobile advertising, promotion, and research“, Journal of Advertising Research, Vol. 47, No. 1, pp. 28-37. ISSN 00218499. DOI 10.2501/S0021849907070043.

[12] Habibi, A. M., Ulman, M., Vaněk, J. and Pavlík, J. (2016) "Measurement and Analysis of Quality of Service of Mobile Networks in Afghanistan - End User Perspective“, AGRIS on-line Papers in Economics and Informatics, Vol. 8, No. 4, pp. 73-84. ISSN 1804-1930. DOI 10.7160/aol.2016.080407.

[13] Habibi, M. A., Ulman, M., Baha, B. and Stočes, M. (2017) „Measurement and Statistical Analysis of End User Satisfaction with Mobile Network Coverage in Afghanistan“, AGRIS on-line Papers in Economics and Informatics, Vol. 9, No. 2, pp. 47-58. ISSN 1804-1930. DOI 10.7160/aol.2017.090204.

[14] Inman, J. J. and Nikolovova, H. (2017) "Shopper-Facing Retail Technology: A Retailer Adoption Decision Framework Incorporating Shopper Attitudes and Privacy Concerns", Journal of Retailing, Vol. 93, No. 1, pp. 7-28. ISSN 0022-4359. DOI 10.1016/j.jretai.2016.12.006.

[15] Johnson, V. L., Kiser, A, Washington, R. and Torres, R. (2018) "Limitations to the rapid adoption of M-payment services: Understanding the impact of privacy risk on M-Payment services“, Computers in Human Behavior, Vol. 79, pp. 111-122. ISSN 0747-5632. DOI 10.1016/j.chb.2017.10.035. 
[16] Jung, J., Chan-Olmsted, S. and Kim, Y. (2013) "From access to utilization: Factors affecting smartphone application use and its impacts on social and human capital acquisition in South Korea", Journalism and Mass Communication Quarterly, Vol. 90, No. 4, pp. 715-735. ISSN 10776990. DOI $10.1177 / 1077699013503163$

[17] Koenigstorfer, J. and Groeppel-Klein, A. (2012) "Consumer acceptance of the mobile Internet", Marketing Letters, Vol. 23, No. 4, pp. 917-928. E-ISSN 1573-059X, ISSN 0923-0645. DOI 10.1007/s11002-012-9206-1.

[18] Köppelová, J. and Jindrová, A. (2017) "Comparative Study of Short-Term Time Series Models: Use of Mobile Telecommunication Services in CR Regions", AGRIS on-line Papers in Economics and Informatics, Vol. 9, No. 1, pp. 77-89. ISSN 1804-1930. DOI 10.7160/aol.2017.090107.

[19] Levesque, N., Durif, F., Boeck, H. and Bilolo, A. (2015) "The impact of Proximity Marketing on consumer reaction and firm performance: A conceptual and integrative model, Americas Conference on Information Systems“, AMCIS 2015, ISBN 978-099668310-4.

[20] Liebana-Cabanillas, F., Marinkovic, V., de Luna, I.R. and Kalinic, Z. (2018) "Predicting the determinants of mobile payment acceptance: A hybrid SEM-neural network approach", Technological Forecasting and Social Change, Vol. 129, pp. 117-130. ISSN 0040-1625. DOI 10.1016/j.techfore.2017.12.015.

[21] Marriott, H. R. and Williams, M. D. (2018) "Exploring consumers perceived risk and trust for mobile shopping: A theoretical framework and empirical study", Journal of Retailing and Consumer Services, Vol.42,pp. 133-146.ISSN 0969-6989.DOI 10.1016/j.jretconser.2018.01.017.

[22] Ojala, T., Kruger, F., Kostakos, V. and Valkama, V. (2012) "Two field trials on the efficiency of unsolicited Bluetooth proximity marketing“, Proceedings of the $11^{\text {th }}$ International Conference on Mobile and Ubiquitous Multimedia, MUM 2012. ISBN 978-145031815.

[23] Olwal, T. O., Djouani. K and Kurien A. M. (2016) "A Survey of Resource Management towards 5G Radio Access Networks“, IEEE Communications Surveys \& Tutorials, Vol. 18, No. 3, pp. 1656-1686. ISSN 1553-877X. DOI 10.1109/COMST.2016.2550765.

[24] Shankar, A. and Datta, B. (2018) "Factors Affecting Mobile Payment Adoption Intention: An Indian Perspective“, Global Business Review, Vol. 19, No. 3, pp. S72-S89, Supplement: S. E-ISSN 0973-0664, ISSN 0972-1509. DOI 10.1177/0972150918757870.

[25] Steckel, J. H., Winer, R. S., Bucklin, R. E., Dellaert, B. G. C., Drèze, X., Häubl, G., Jap, S. D., Little, J. D. C., Meyvis, T., Montgomery, A. L., Rangaswamy, A. (2005) "Choice in Interactive Environments“, Marketing Letters, Vol. 16, No. 3-4, pp. 309-320. E-ISSN 1573-059X, ISSN 0923-0645. DOI 10.1007/s11002-005-5894-0.

[26] Šimek, P., Jarolímek, J. and Masner, J. (2014) "Cross-Platform User Interface of a Web Application in Agrarian Sector", Agris on-line Papers in Economics and Informatics, Vol. 6, No. 4, pp. 155-160, ISSN 1804-1930.

[27] Ulman, M., Ualiyev, N. S. and Toregozhina, M. B. (2016) "Do Digital Public Services Matter? A Comparative Study of the Czech Republic and the Republic of Kazakhstan“, AGRIS on-line Papers in Economics and Informatics, Vol. 8, No. 2, pp. 121-133. ISSN 1804-1930. DOI 10.7160/aol.2016.080210.

[28] Vaněk, J., Kánská, E., Jarolímek, J. and Šimek, P. (2010a) "State and evaluation of information and communication technologies development in agricultural enterprises in Czech Republic", Plant, Soil and Environment, Vol. 56, No. 3, pp. 143-147. ISSN 1214-1178.

[29] Vaněk J., Šimek P., Vogeltanzová T., Červenková E. and Jarolímek J. (2010b) "ICT in Agricultural Enterprises in the Czech Republic - Exploration 2010“, Agris on-line Papers in Economics and Informatics, Vol. 2, No. 3, pp. 69-75. ISSN 1804-1930.

[30] Varki, S. and Rust, R. T. (1998) "Technology and Optimal Segment Size“, Marketing Letters, Vol. 9, No. 2, pp. 147-167. E-ISSN 1573-059X, ISSN 0923-0645. DOI 10.1023/A:1007956915353. 
[31] Zhu, X. L., Hou, Z. F., Hu, D. H. and Zhang, J. (2016) "Secure and Efficient Mobile Payment Using QR Code in an Environment with Dishonest Authority", in "Security, Privacy, and Anonymity in Computation, Communication, and Storage", $9^{\text {th }}$ International Conference, SpaCCS 2016, Zhangjiajie, China, November 16-18, 2016, Proceedings, pp. 452-465. ISSN 0302-9743. DOI 10.1007/978-3-319-49148-6_37.

[32] Wang, Y. S., Lin, H. H. and Luarn, P. (2006) "Predicting consumer intention to use mobile service“, Information Systems Journal, Vol. 16, No. 2, pp. 157-179, ISSN 13501917. DOI 10.1111/j.1365-2575.2006.00213.x.

[33] Xu, H. and Gupta, S. (2009) "The effects of privacy concerns and personal innovativeness on potential and experienced customers' adoption of location-based services“, Electronic Markets, Vol. 19, No. 2-3, pp. 137-149, ISSN 10196781. 